\title{
Observando os grupos multifamiliares em uma instituição psiquiátrica
}

\author{
Observing multifamily groups in a psychiatric institution
}

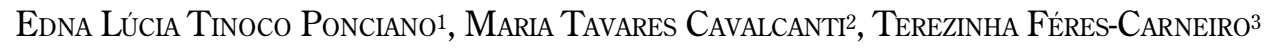 \\ 1 Pós-doutorado pela Fundação de Amparo à Pesquisa do Estado do Rio de Janeiro (FAPERJ) da Pontifícia Universidade Católica do Rio de Janeiro (PUC-Rio), Rio de Janeiro, RJ. \\ 2 Professora adjunta do Instituto de Psiquiatria da Universidade Federal do Rio de Janeiro (UFRJ), Rio de Janeiro, RJ. \\ 3 Professora titular do Departamento de Psicologia da PUC-Rio, Rio de Janeiro, RJ.
}

Recebido: 2/1/2009 - Aceito: 9/4/2009

\begin{abstract}
Resumo
Contexto: Investigaram-se as diversas práticas que incluem a família em uma instituição psiquiátrica. Destacou-se o grupo multifamiliar, que é um espaço privilegiado de atendimento. Objetivo: Buscou-se compreender como as famílias são atendidas, levantando as principais questões observadas em diversos grupos. Métodos: Como método, utilizou-se a observação participante, sendo realizada no setor de atendimento infanto-juvenil, no Hospital-Dia, no Centro de Doença de Alzheimer e outras demências (CDA) e no Programa de Estudos e Assistência ao Uso Indevido de Drogas (PROJAD). Resultados: Observou-se que no grupo multifamiliar a catarse, o relato dos conflitos e o compartilhamento de informações produzem um efeito de rede. Os familiares trabalham juntos e as famílias se engajam em uma conversação que ajuda a construir uma comunidade de apoio. Conclusões: Em razão das questões apresentadas, considerou-se importante discutir o grupo multifamiliar, relacionando-o à terapia de grupo multifamiliar, aos grupos de psicoeducação e ao trabalho com rede social. Concluiu-se que a rotina da instituição psiquiátrica tem incluído a família, mas é necessário analisar a demanda e sistematizar os atendimentos feitos em grupo.
\end{abstract}

Ponciano ELT, et al. / Rev Psiq Clín. 2010;37(2):43-7

Palavras-chave: Grupo multifamiliar, terapia, psicoeducação, rede social.

\begin{abstract}
Context: Several practices that include the family in a psychiatric institution were investigated. The focus was on the multifamily group, which is a privileged space for assistance. Goal: There was an attempt to understand how families are assisted, raising the main questions observed in different groups. Methods: Participant observation was conducted in the child and youth sector, the Day-Hospital, the Center for Alzheimer Disease and other dementia (CDA), and in the Program for Studies and Assistance in Inappropriate Use of Drugs (PROJAD). Results: It was observed that in the multifamily group the catharsis, the account of conflicts and the sharing of information produce a network effect. Family members work together, and families engage in a conversation that helps building a supportive community. Discussion: In the face of the questions raised, it is important to discuss multifamily group, relating it to multifamily group therapy, groups of psychoeducation, and to the work in social networks. It was concluded that the routine in a psychiatric institution has been including the family, but it is necessary to analyze the demands and systematize the assistance conducted with groups.
\end{abstract}

Ponciano ELT, et al. / Rev Psiq Clín. 2010;37(2):43-7

Keywords: Multifamily group, therapy, psychoeducation, social network.

\section{Introdução}

A família de um paciente psiquiátrico demanda tratamento, estando sujeita à alta carga de estresse, especialmente para os membros responsáveis pelo cuidado ${ }^{1-5}$. Construir um projeto de tratamento para a família visa a prepará-la para lidar com o paciente, evitando o efeito da sobrecarga ${ }^{6,7}$. Nessa perspectiva, o impacto do transtorno mental pode ser reduzido pelas intervenções terapêuticas da equipe de Saúde Mental, que pode se estender à rede de suporte social e de apoio comunitário, o que alivia o contato com os serviços de saúde, ajudando os familiares na interação e na gestão da vida cotidiana dos pacientes e fortalecendo a parceria família-instituição. Uma forma privilegiada de oferecer assistência às famílias tem sido a de reuni-las em um grupo.

A ideia de tratar famílias, em uma terapia de grupo, surgiu em 1950, no Hospital do estado de Nova York, com Peter Laqueur. No início, trabalhou-se, principalmente, com famílias de esquizofrênicos e, depois, ampliou-se para variados diagnósticos, em diferentes tipos de serviços de Saúde Mental. Os primeiros grupos foram descritos como workshops de comunicação familiar, sendo realizados com quatro ou cinco famílias ${ }^{8,9}$. O objetivo era o de buscar uma melhora da comunicação e uma maior compreensão das situações vividas, fazendo com que as famílias aprendessem umas com as outras, a partir da troca de experiências. Esses primeiros grupos tinham intervalos semanais, com cada encontro durando em torno de uma a duas horas, sendo formados com ou sem a presença do paciente identificado.

Resumindo as características dos primeiros grupos de terapia de grupo multifamiliar: eram compostos por quatro ou cinco famílias de pacientes internados ou de ambulatório; os pacientes podiam participar ou não e os familiares que participavam eram os pais, os irmãos, os cônjuges e as crianças; os encontros eram semanais com duração em torno de duas horas; quanto à organização e à estrutura dos grupos, estavam presentes, no setting terapêutico, o terapeuta, o coterapeuta e observadores (terapeutas em formação); os encontros eram à noite, para que tivessem a maior participação possível, incluindo os familiares que trabalhavam; a sala era ventilada, tinha de 25 a 30 lugares e também equipamento de filmagem, usado tanto para objetivos terapêuticos quanto para objetivos de pesquisa; os grupos eram abertos; as famílias eram selecionadas a partir de um fator em comum (tal como diagnóstico psiquiátrico, nível educacional ou status econômico); estabelecido esse ponto em comum, os grupos eram formados misturando origem religiosa, orientação partidária, idade, procurando evitar uma falsa unidade, que poderia levar o grupo a uma discussão superficial. 
Em relação ao processo grupal, a primeira tarefa do terapeuta era explicar que não iria trabalhar com a ideia de um paciente primário (identificado), que se oporia aos membros saudáveis da família. $\mathrm{O}$ olhar do terapeuta estava direcionado para os padrões que determinavam um distúrbio interacional, envolvendo a família inteira e visava a ajudar a todos. Durante o processo de grupo, as famílias se tornavam coterapeutas, ajudando umas às outras a encontrarem possibilidades de mudança e o enfrentamento dos problemas.

A terapia de grupo multifamiliar tem sua especificidade determinada pela soma de duas propostas (Tabela 1), a terapia de família e a terapia de grupo, e pela soma de dois grupos, o natural (familiar) e o de desconhecidos, constituindo-se como uma terceira opção. Ao serem somadas, essas características definem a proposta da terapia de grupo multifamiliar, diferenciando-a de outras terapias de grupo (Tabela 2).

Tabela 1. Comparação entre terapia de família e terapia de grupo

\begin{tabular}{l|l}
\hline Terapia de família & Terapia de grupo \\
\hline Grupo natural & Grupo de desconhecidos \\
\hline $\begin{array}{l}\text { Objetivo: abordar as relações, levando } \\
\text { o foco do indivíduo para a interação } \\
\text { familiar }\end{array}$ & $\begin{array}{l}\text { Objetivo: levar um grupo de } \\
\text { desconhecidos a uma interação } \\
\text { significativa }\end{array}$ \\
\hline $\begin{array}{l}\text { Setting terapêutico: amplia-se para } \\
\text { incluir os membros de uma família que } \\
\text { já têm uma história em comum }\end{array}$ & $\begin{array}{l}\text { Setting terapêutico: amplia-se formando } \\
\text { um grupo de desconhecidos que passam } \\
\text { a ter uma história em comum }\end{array}$ \\
\hline
\end{tabular}

Tabela 2. Comparação entre terapia de grupo multifamiliar e terapia de grupo

\begin{tabular}{l|l}
\hline Terapia de grupo & Terapia de grupo multifamiliar \\
\hline $\begin{array}{l}\text { A história do grupo começa com a } \\
\text { formação do grupo }\end{array}$ & $\begin{array}{l}\text { A história do grupo é, ao mesmo } \\
\text { tempo, anterior à formação do grupo, } \\
\text { no caso de cada família, e começa com } \\
\text { o grupo, no caso dos que não são da } \\
\text { mesma família }\end{array}$ \\
\hline $\begin{array}{l}\text { O processo envolve tanto o grupo } \\
\text { como um todo quanto cada indivíduo } \\
\text { separadamente }\end{array}$ & $\begin{array}{l}\text { O processo envolve tanto o grupo } \\
\text { como um todo quanto uma unidade } \\
\text { familiar distinta e/ou um indivíduo }\end{array}$ \\
\hline $\begin{array}{l}\text { A intensidade da experiência é } \\
\text { produzida à medida que aumenta } \\
\text { a interação entre os membros que } \\
\text { formam o grupo }\end{array}$ & $\begin{array}{l}\text { A intensidade da experiência é } \\
\text { produzida por se estar diante de } \\
\text { membros da mesma família e à } \\
\text { medida que aumenta a interação entre } \\
\text { os que não são da mesma família }\end{array}$ \\
\hline $\begin{array}{l}\text { Não há encontros para além do grupo, } \\
\text { caracterizando a preservação do } \\
\text { espaço terapêutico }\end{array}$ & $\begin{array}{l}\text { Há encontros para além do grupo } \\
\text { (sendo da mesma família ou não), } \\
\text { caracterizando a ampliação do espaço } \\
\text { interacional }\end{array}$ \\
\hline
\end{tabular}

Podem ser utilizados genogramas, colagem, dramatização, escultura familiar, entre outras técnicas, trazidas da Terapia de Família ${ }^{10}$. É importante também observar o processo grupal que transforma a experiência dos envolvidos. Essa transformação pode ser notada pela presença dos fatores terapêuticos ${ }^{11}$. É interessante ressaltar dois fatores que ocorrem, frequentemente, nos grupos multifamiliares: o compartilhamento de informações, um processo educacional que ocorre espontaneamente entre as famílias, e a catarse, expressão de fortes emoções que é mais proveitosa quando faz parte de um processo interacional.

A terapia de grupo multifamiliar não é a única alternativa para reunir famílias em um grupo. Há outras abordagens. Destaca-se, comparativamente, o grupo multifamiliar com objetivos psicoeducacionais, que é uma proposta indicada, principalmente, para o paciente psicótico e seus familiares. Nesses casos, costuma ser feita uma combinação de grupos psicoeducacionais com a terapia de família. Algumas pesquisas demonstram que o enfoque psicoeducacional, oferecido tanto aos pacientes quanto aos familiares, diminui a recaída e a re-hospitalização ${ }^{12-18}$. Geralmente, nos grupos psicoeducacionais com familiares, o membro psicótico não é incluído, sendo incluído somente na sessão de terapia de família.

No modelo psicoeducacional, os familiares devem aprender, por exemplo, como a medicação pode modificar o comportamento do paciente, fazendo com que a família adquira habilidade para enfrentar situações previsíveis. Outra ênfase importante encontra-se na resolução de um problema, tal como a aceitação da medicação, o efeito do uso de drogas e álcool, desacordos familiares, comportamentos agressivos e suicidas etc. Em cada encontro do grupo multifamiliar, um problema ou objetivo específico é selecionado. Todos os membros do grupo são convidados a listar as possíveis soluções, discutir as vantagens e desvantagens e finalmente escolher a solução que melhor se adapta à situação, sendo estabelecido um plano detalhado de execução.

Alguns autores defendem a eficácia da abordagem psicoeducacional para o início do tratamento, nos programas comunitários e na prevenção da recaída. Entretanto, a forte ênfase na psicoeducação formal e na resolução objetiva de problemas não se ajusta completamente ao modelo e à prática cuja perspectiva é a da relação interpessoal 19,20 . Adotando esse enfoque, a terapia de grupo multifamiliar é a mais apropriada.

A intensidade de uma terapia de grupo multifamiliar permite que se observe a interação familiar, como as famílias lidam com o paciente, como eles falam entre si sobre problemas e questões concretas, como resolvem problemas, como se comunicam e como lidam com os conflitos. Essa informação detalhada ajuda a escolha de intervenções específicas, que devem ser construídas com as famílias. Quando um grupo é composto por familiares que trabalham juntos, há o incremento da troca, fazendo com que o terapeuta funcione como um facilitador. As famílias se engajam em um movimento de conversação, desenvolvendo um tipo de processo psicoeducacional de família para família. Também constroem pequenas comunidades, alargando suas redes sociais, que persistem mesmo após longo período de término da terapia. Essa abordagem, portanto, não exclui a psicoeducação, mas a torna menos formal.

Criar e/ou ativar uma rede social aumenta exponencialmente as chances de a família participar e colaborar com o tratamento. O efeito da rede é um fenômeno que possibilita uma nova etapa de interação, ajudando a desconstruir conflitos e a reconstruir possibilidades de relacionar-se. A rede familiar de um paciente psiquiátrico faz parte de uma constelação familiar perturbada ${ }^{21}$. Por meio da experiência com a rede, observa-se a necessidade de trabalhar não só a rede familiar, mas todas as pessoas importantes na vida dos pacientes e/ou as pessoas que mantêm contato com o paciente. Isso diminui a sobrecarga do núcleo familiar, pois toda a comunidade participa ajudando a família de algum modo.

Além da ampliação territorial do espaço terapêutico, as intervenções na rede social mobilizam importantes recursos. Os habitantes das cidades precisam redescobrir recursos e relações de apoio que se diluíram à medida que foram rompidos os vínculos com a família extensa e a comunidade. No efeito de criação de redes, acredita-se encontrar a razão pela qual o grupo multifamiliar é uma forma privilegiada de cuidado à família em uma instituição psiquiátrica.

Neste artigo, destacam-se os grupos multifamiliares, que ocorrem em diversos setores do Instituto de Psiquiatria (IPUB) da Universidade Federal do Rio de Janeiro (UFRJ), apresentando e discutindo os dados obtidos a partir da observação participante de variados grupos. Percebe-se que o grupo multifamiliar é escolhido à medida que se torna necessário criar um espaço de atendimento à família, no qual a troca de experiências e de ajuda mútua é fundamental.

\section{Metodologia}

Utilizamos uma metodologia qualitativa, desenvolvida em três etapas. Neste artigo, apresentamos, resumidamente, os dados da primeira etapa e foram discutidos os da terceira. A apresentação e a discussão da segunda fase encontram-se em outro artigo ${ }^{22}$. Descrevemos as três fases, a fim de que seja possível visualizar o desenho da pesquisa: 1) levantamento do modo como são recebidas 
as famílias, nos diversos setores do IPUB da UFRJ, obtendo esses dados ao entrevistar os coordenadores de cada serviço. A partir dessas entrevistas, realizadas pela primeira autora, conheceu-se a organização dos serviços e obteve-se a permissão de entrar em contato com os profissionais de cada setor; 2) entrevista semidirigida, realizada pela primeira autora, com os diversos profissionais que lidam com famílias, procurando identificar quais são as propostas de intervenção e os referenciais teóricos e técnicos adotados; 3) observação participante de grupos multifamiliares. Nessas atividades, a primeira autora contou com o auxílio de alunos da graduação de medicina da UFRJ, da Psicologia da Universidade Santa Úrsula (USU) e da especialização em Terapia de Família do IPUB/UFRJ.

Os grupos multifamiliares foram identificados a partir das entrevistas realizadas com os coordenadores dos serviços, que nos indicaram os profissionais que deveriam ser consultados. Em contato com os profissionais responsáveis, pôde-se combinar o modo como se daria a apresentação da pesquisa, assim como se daria a inserção nos grupos. Não se tinha o objetivo de fazer uma avaliação do serviço e sim compreender o modo como as famílias eram atendidas em grupo. Para tanto, a observação participante possibilitou um contato direto com a experiência vivida nos grupos multifamiliares.

Após a apresentação da pesquisa e a partir do consentimento dos familiares, registrado em ata, que, em todos os grupos, é redigido por um profissional e/ou por um aluno da instituição, foi iniciada a observação participante, prevista para ocorrer em um período de seis meses. Os encontros foram registrados, a partir de anotações, enquanto ocorria a observação participante. De nossas anotações, retiraram-se algumas cenas exemplares da experiência nos grupos, que são analisadas a seguir.

\section{Resultados}

Apresentamos, resumidamente, os serviços que possuem grupos multifamiliares, de acordo com as informações obtidas com os respectivos coordenadores, destacando as questões relativas à forma de lidar com a família. Em seguida, são apresentados os dados relativos à observação participante.

\section{Atendimento infanto-juvenil}

Há dois setores voltados para o atendimento de criança e adolescente: um serviço diário e o ambulatório. No primeiro, há várias atividades dirigidas especificamente para as famílias (grupos de familiares, refeições com os familiares, assembleias, terapia de família etc.). No segundo, há um número menor de atividades, mas o contato com as famílias é intenso e visto como necessário. Observou-se um grupo ocorrido semanalmente no serviço de atendimento diário, que funciona nos moldes de um hospital-dia.

\section{Hospital-Dia}

No Hospital-Dia Luiz Cerqueira (CAD), há poucas atividades com famílias, embora sua maior participação seja prevista. Observou-se um grupo mensal, que reúne a equipe, formada por profissionais variados, estudantes e os familiares.

\section{Centro de Doença de Alzheimer e outras demências (CDA)}

A partir de um primeiro atendimento, pode ser feito um encaminhamento para o profissional da Psicologia, para diversas atividades em grupo (fisioterapia, musicoterapia etc.) e para o grupo de familiares. Nesse grupo, participam familiares e cuidadores do paciente com Alzheimer e outras demências. Os encontros ocorrem duas vezes por semana.

\section{Programa de Estudos e Assistência ao Uso Indevido de Drogas}

O Programa de Estudos e Assistência ao Uso Indevido de Drogas (PROJAD) desenvolve atividades de assistência para aqueles que têm problemas relativos ao uso de substâncias psicoativas. A família, desde o início, é uma ativa participante do processo, acompanhando o paciente e apresentando problemas que podem estar relacionados ao uso indevido de drogas. O grupo de familiares ocorre quinzenalmente.

Os grupos multifamiliares observados têm como objetivos a troca de experiência e de informações, o esclarecimento de dúvidas quanto aos sintomas, aos medicamentos e, principalmente, às formas de lidar com o paciente. Observou-se pouco tempo disponível para a catarse, a expressão de emoções, o relato de histórias e o relato pessoal, embora estes sempre estejam presentes. A troca tende à objetividade voltada ao encontro da solução de problemas específicos, ligados à temática dos grupos. Todos os grupos possuem um ou mais coordenadores, que se alternam.

Os grupos são formados pelos parentes e cuidadores dos pacientes, atendidos nesses setores. Geralmente, são representadas de quatro a cinco famílias. Cada grupo tem uma temática, especificamente ligada à sua clientela. Os pacientes não participam dos grupos, à exceção do Hospital-Dia, que, ocasionalmente, convida os pacientes a estarem presentes na reunião dos familiares. Nesse caso, a reunião costuma ter um tema previamente estabelecido, que interessa a todos.

A seguir, foram descritos três acontecimentos, recorrentes em todos os grupos, e algumas cenas observadas, destacadas para ilustração:

1) Catarse: quando um familiar fala de si, de sua sobrecarga, sua própria doença ou mal-estar; é um momento de intensa emoção, mas há pouco tempo e o objetivo não é a terapia.

Um pai inicia o grupo falando sobre seu filho, ressaltando a imprevisibilidade do seu comportamento. Diz que o filho busca o afeto da mãe. Enquanto fala, o pai olha para a mãe. Parece estar observando a reação dela. A mãe abaixa a cabeça e não fala nada. O pai continua falando sobre o que tem feito com o filho. Diz: "Estou aprendendo violão. Para mim, é uma terapia. Tenho tentado passar isso para o meu filho". A coordenadora do grupo se dirige à mãe, que responde: "As coisas estão indo. Não quero falar. Só posso dizer que não está muito ruim comigo". A filha reage e pergunta à mãe: "É alguma coisa comigo?". Essa família, sempre presente, não costuma falar tanto. Nesse encontro, diferentemente de outros dias, estão sentados separadamente. Parece estar acontecendo algo. Outra mãe fala que às vezes surge uma dúvida quanto ao comportamento do filho, se está ou não usando drogas. Fica com receio, mas acredita que o filho pode conquistar a confiança dela. Conta várias histórias com o filho e o pai dele. Fala sobre promessas e recaídas, relembrando o início do tratamento. O pai, sentado ao seu lado, como em todos os encontros, confirma o relato e o aumento de confiança. Enquanto isso, a mãe da primeira família mencionada, aquela que não queria falar, tem uma reação que surpreende a todos. Começa a chorar, não fala nada e sai da sala. Uma estagiária vai atrás dela. A filha diz, espantada, que não entende o que está acontecendo com a mãe. Acha que ela deve estar com algum problema pessoal. Relata que seu irmão está bem, não teve recaída, só está muito carente, demandando muita atenção. Outros familiares continuam falando, mas há um clima tenso. A filha sai atrás da mãe e o pai continua sentado. Uma terceira mãe relata as queixas que têm a respeito do tratamento. Ela é médica e observa tudo por esse ângulo. Aos poucos, vai ficando irritada com a intervenção da coordenadora, que pede que ela fale como mãe. Ela se recusa e quer falar sobre o direito dos familiares. Lembra que, em encontros anteriores, conversou com um pai que é advogado. A coordenadora informa que ele faleceu. Ela chora. Outros membros do grupo choram. A tristeza invade o grupo. A mãe que saiu não retornou. Posteriormente, fica-se sabendo que ela está investigando um câncer de mama e não havia falado para ninguém de sua família. (Familiares dos pacientes do PROJAD)

2) Conflitos entre os familiares e o paciente: relatos que suscitam uma reação intensa dos familiares; quando o conflito é muito absorvente, o familiar é encaminhado à terapia de família.

Uma pessoa começa a falar identificando-se como madrinha de uma paciente e queixa-se da ausência de limites. Narra situações em que a paciente "dá show" e a madrinha corta, ameaçando-a: "se continuar assim não vai mais poder pedir a benção, nem me chamar de madrinha”. Um pai de outra paciente acrescenta que é necessário 
ajudar os pacientes a se tornarem independentes. A madrinha, ao ouvir isso, reage com irritação. $\mathrm{O}$ coordenador do grupo intervém. O pai pede desculpa. A madrinha continua a falar afirmando que não vai mudar e que ele não conhece a história. Fala que os pais da paciente nunca deram limites a ela e que nunca apanhou. A madrinha não quer mais deixar de sair para cuidar da afilhada: "estou dando um basta". Outros familiares começam a falar ao mesmo tempo. A irmã de um paciente narra sua história e diz: "é preciso dar limites com muita tranquilidade". A madrinha continua reagindo irritada. Parece sentir-se ofendida. O pai, que já havia falado, retoma a palavra e pergunta à madrinha qual o grau de parentesco que tem com a paciente. Ela responde que são irmãs. Os pais, que ela havia mencionado anteriormente, são os mesmos. Fica claro, então, que há uma história, uma dinâmica familiar, presente no conflito apresentado. A reunião está no fim. Uma mãe está ansiosa para falar de seu filho. Não há mais tempo. Um membro da equipe de profissionais afirma a importância dos temas levantados nesse encontro e que o serviço também é para os familiares. Outros membros da equipe confirmam e acrescentam que alguns casos devem ser encaminhados para o setor de família, em que há terapia de família. Terminada a reunião, um pai comenta: "hoje a reunião foi muito boa”. (Familiares dos pacientes do Hospital-Dia)

3) Compartilhamento de informações: os familiares falam entre si, oferecem conselhos e trocam experiências. A partir dessa troca, os membros do grupo constroem uma rede de apoio. Um dos temas mais comentados é o do uso da medicação e o do processo de tratamento.

Nesse encontro, os pais relatam que seus filhos recusam-se a tomar remédios. Um pai afirma que precisa enganar o filho para dar-lhe a medicação e acrescenta que tem medo dos possíveis efeitos: "tenho medo de dar remédio para meu filho, pois, se ele tiver qualquer reação e morrer, eu vou ser preso". A fala desse pai gera uma discussão. Outros relatam ter experiência semelhante. Outra mãe acrescenta que sua filha apresenta vários efeitos colaterais (vômito, dor de cabeça e enjoo) e pergunta por quanto tempo terá de tomar remédio. Outras mães identificam-se e afirmam que seus filhos também passam mal. Os pais têm a oportunidade de trocar ideias e dividir suas preocupações e angústias. Uma solução imediata pode não ser encontrada, mas eles encontram um espaço de acolhimento e de busca de alternativas para minorar o sofrimento. (Pais de adolescentes do setor de atendimento infanto-juvenil)

Uma filha, cuja mãe está com Alzheimer, relata sua preocupação a respeito do tratamento. Não tem tido apoio de sua irmã e de seu pai, que não aceitam a doença da mãe. Sente-se só. Fala ansiosamente. Está muito angustiada. O grupo acolhe. Alguns confirmam a dificuldade de aceitar a doença e outros fazem algumas sugestões, como insistir em trazer o pai, encontrar um tratamento para ele e para a irmã também, contar com a ajuda de amigos, entre outras. Após várias sugestões, com a ajuda da coordenadora do grupo, a angústia dessa filha é acolhida e ela começa a falar de seus sentimentos, seus projetos adiados, seus medos, sua tristeza. O grupo novamente acolhe e alguns dividem seus sentimentos, como nessa fala: "eu tenho vontade de fugir". São feitos outros relatos e cada membro do grupo, ao falar de sua história, retoma a história anterior para acrescentar algo. A conclusão do grupo se apresenta na seguinte fala: “é difícil aceitar que uma pessoa não seja mais o que já foi”. (Familiares de paciente com Alzheimer - CDA)

\section{Discussão}

Os três pontos acima descritos, e as respectivas cenas, permitem que se torne conhecida, de forma concisa, a experiência de reunir famílias em um grupo. Os familiares e os cuidadores utilizam o espaço para apresentarem suas queixas, seus sentimentos e suas histórias, revelando a alta carga de estresse a que estão submetidos. O grupo constitui-se como um espaço privilegiado para aliviar essa carga e encontrar soluções alternativas. As cenas descritas demonstram como há interação e troca de experiência entre as famílias. Mais pesquisas precisariam ser feitas para que se pudesse compreender qual efeito é produzido com a continuidade dos encontros.
Embora nenhum dos grupos observados tenha a perspectiva de terapia ou de psicoeducação, os acontecimentos e as cenas descritas demonstram haver momentos em que se fazem necessários tanto o recurso terapêutico quanto o recurso da informação sistematizada. A catarse e o relato dos conflitos familiares indicam a demanda dessas famílias para terem um espaço terapêutico no qual possam trabalhar suas emoções e a dinâmica familiar. Inicialmente, acredita-se que o grupo produz um bom resultado ao acolher essas famílias, mas se desconhece qual seria o benefício de um processo terapêutico sistematizado. Após esse momento de catarse e de relato de conflitos familiares, tende-se a um enfoque objetivo e encaminhamento para a Terapia de Família. Pergunta-se como seria se o grupo trabalhasse essa demanda visando à construção de uma proposta de terapia de grupo multifamiliar.

Os grupos não se constituem como terapia, mas apresentam fatores que são terapêuticos. Ainda que a interação entre os membros do grupo não seja explorada durante o processo grupal, ela aparece como um tema importante em vários momentos. A interação proporciona uma transformação que pode ser notada pela presença de dois dos fatores terapêuticos: o compartilhamento de informações e a catarse. Em relação à catarse, principalmente, acredita-se que a expressão de fortes emoções poderia ser mais proveitosa se fosse vista como parte de um processo relacional, trabalhado em um projeto de terapia.

Quanto ao compartilhamento de informações, dois pontos devem ser analisados: há uma troca espontânea de informações e, consequentemente, forma-se uma rede de apoio, sendo comum os familiares continuarem o grupo em conversas informais, combinando encontros fora da instituição, o que torna secundária a participação do coordenador do grupo. Desse modo, os grupos são uma importante fonte de informação sobre medicação e processo de tratamento. Isso ocorre pela troca de experiência mais do que pela sistematização advinda dos profissionais. Há, portanto, um efeito psicoeducacional em que a informalidade, gerada pela troca de experiência, contribui para a criação e o fortalecimento de uma rede social de apoio para os familiares.

Mais uma vez, pensa-se que o grupo produz um benefício para os familiares, mas indaga-se sobre os possíveis efeitos, caso essa demanda fosse trabalhada de forma sistematizada, oferecendo também grupos de psicoeducação. A informação sistematizada pode ajudar a diminuir o impacto da doença mental, aliviando o estresse, já que algumas situações são previsíveis e, por isso, podem ser aprendidas, ajudando os familiares a lidarem com o paciente.

A presente análise permite afirmar que, no grupo multifamiliar, a catarse, o relato dos conflitos e o compartilhamento de informações produzem um efeito terapêutico, psicoeducativo e de rede. Os familiares trabalham juntos e as famílias se engajam em uma conversação que ajuda a construir uma comunidade de trocas de informação e de apoio. Por conseguinte, o grupo contribui para a formação de uma rede social que diminui a sobrecarga e alivia o estresse.

Cada grupo observado tem uma situação particular que cria uma demanda específica. Não cabe, com essa pesquisa, definir o formato e o objetivo dos grupos. No entanto, acredita-se que observar estas três possibilidades de abordagem - terapia, psicoeducação e formação de uma rede social de apoio - pode auxiliar em um projeto de construção de atendimento às famílias.

\section{Considerações finais}

A análise dos dados permitiu a identificação de três pontos relacionados, que devem ser abordados mais detidamente, a partir de outras pesquisas:

- Despreparo e sobrecarga da família, na ausência de uma rede de apoio;

- Diversificação dos cuidados oferecidos à família, incluindo a terapia de grupo multifamiliar;

- Sistematização de um trabalho de informação para as famílias (psicoeducação). 
Considera-se que, apesar das dificuldades e das questões ainda não respondidas, os grupos multifamiliares do IPUB obtêm sucesso por propiciar a troca de experiências e a ajuda mútua. As famílias são beneficiadas ao encontrarem um espaço no qual podem se sentir menos solitárias e isoladas. Desse ponto em diante, é necessário que se atente para as demandas criadas e para a possibilidade de serem gerados outros espaços que podem ter a forma de grupos multifamiliares com o objetivo de oferecer informação sistematizada (psicoeducação) e/ou terapia de grupo.

\section{Agradecimentos}

À Fundação de Amparo à Pesquisa do Estado do Rio de Janeiro (Faperj) agradecemos a bolsa de pesquisador-associado concedida à Edna Lúcia Tinoco Ponciano para a realização desta pesquisa.

\section{Referências}

1. Bandeira M, Barroso SM. Sobrecarga das famílias de pacientes psiquiátricos. J Bras Psiquiatr. 2005;54(1):34-46.

2. Barroso SM, Bandeira M, Nascimento E. Sobrecarga de familiares de pacientes psiquiátricos atendidos na rede pública. Rev Psiq Clín. 2007;34(6):270-7.

3. BRASIL. Ministério da Saúde. Secretaria Executiva. Legislação em saúde mental 1990-2002. 3.ed. Revista e atualizada - Brasília, DF: Ministério da Saúde; 2002.

4. Melman J. Família e doença mental: repensando a relação entre profissionais de saúde e familiares. São Paulo: Escrituras Editora; 2001.

5. Rosa L. Transtorno mental e o cuidado na família. São Paulo: Cortez; 2003.

6. Lucksted A, Dixon L. Quality of care in services to family members of people with serious mental illnesses. Ment Healt Serv Res. 1999;1(4):223-30.

7. Pinsof WM, Wynne LC. The effectiveness and efficacy of marital and family therapy: introduction to the special issue. J Mar Fam Ther. $1995 ; 21(4): 341-2$
8. Guerin P. Family therapy: theory and practice. New York: Gardner Press; 1976.

9. Asen E. Multiple family therapy: an overview. J Fam Ther. 2002;24(1): 3-16.

10. Nichols M, Schwartz R. Terapia familiar: conceitos e métodos. Porto Alegre: Artmed; 1998.

11. Yalom I. Psicoterapia de grupo: teoria e prática. Porto Alegre: Artmed; 2006.

12. Goldstein MJ, Miklowitz DJ. The effectiveness of psychoeducational family therapy in the treatment of schizophrenic disorders. J Mar Fam Ther. 1995;21(4):361-75.

13. Mcfarlane WR, Lukens E, Link B, Dushay R, Deakins SA, Newmark M, et al. Multiple-family groups and psychoeducation in the treatment of schizophrenia. Arch Gener Psychiatr. 1995;52(8):679-87.

14. Fadden G. Research update: psychoeducational family interventions. J Fam Ther. 1998;20(3):293-309.

15. Bustillo J, Lauriello J, Horan W, Keith S. The psychosocial treatment of schizophrenia: an update. Am J Psychiatr. 2001;158(2):163-75.

16. Mcfarlane W. Multifamily groups in the treatment of severe psychiatry disorders. New York: The Guilford Press; 2004.

17. Asen E, Schuff H. Psychosis and multifamily group therapy. J Fam Ther. 2006;28(1):58-72.

18. Knapp P, Isolan L. Abordagens psicoterápicas no transtorno bipolar. Rev Psiq Clín. 2005;32(1):98-104.

19. Beach S, Kaslow N. Relational disorders and relational processes in diagnostic practice: introduction to the special section. J Fam Psych. 2006;20(3):353-5.

20. Beach S, Wamboldt M, Kaslow N, Heyman R, Reiss D. Describing relationship problems in DSM-V: toward better guidance for research and clinical practice. J Fam Psych. 2006;20(3):359-68.

21. Speck RV, Attneave CL. Redes familiares. Buenos Aires: Amorrortu editores; 1973.

22. Ponciano ELT, Cavalcanti, MT, Féres-Carneiro T. Cuidando das famílias: uma tarefa de psicólogos e psiquiatras no IPUB/UFRJ. Rev Psiquiatr Rio Gd. Sul. 2009;31(1):32-9. 